\title{
Bayesian analysis of geographical variation in the incidence of Type I diabetes in Finland
}

\author{
M. Rytkönen ${ }^{1}$, J. Ranta ${ }^{2}$, J. Tuomilehto ${ }^{1}$, M. Karvonen ${ }^{1}$ for the SPAT Study Group and the Finnish Childhood \\ Diabetes Registry Group* \\ ${ }^{1}$ National Public Health Institute, Department of Epidemiology and Health Promotion, Diabetes and Genetic Epidemiology Unit, \\ Helsinki, Finland \\ ${ }^{2}$ Rolf Nevanlinna Institute (RNI), University of Helsinki, Helsinki, Finland
}

\section{Abstract}

Aims/hypothesis. In Finland, the incidence of Type I (insulin-dependent) diabetes mellitus among children aged 14 years or under is the highest in the world. The increase in incidence is approximately $3 \%$ per year. A marked geographical variation in incidence was reported in Finland during the late 1980s. Our aim was to explore the most recent regional pattern in incidence of Type I diabetes in Finland.

Methods. Data on the nationwide incidence of childhood diabetes in Finland was obtained from the Prospective Childhood Diabetes Registry for the periods 1987-1991 and 1992-1996. Population data was obtained from the National Population Registry. The geographical pattern of incidence was studied applying a Bayesian hierarchical approach and Geographical Information Systems. The inferences from the data was based on the estimated geographical intensity of diabetes.
Results. There was a clear evidence of geographic variation for the risk of childhood diabetes during the entire 10-year period. The high-risk areas were found in the wide belt crossing the central part of Finland. Comparison of the estimated intensity of diabetes between the two 5-year periods showed that the geographical pattern of diabetes risk has changed over time. Our analyses also confirmed the existence of a few persistent high-risk and low-risk areas in Finland.

Conclusion/interpretation. The finding of high-risk areas of childhood Type I diabetes suggests that specific genetic or environmental risk factors have become greater in certain geographic locations in Finland. [Diabetologia (2001) 44 [Suppl 3]: B 37-B 44]

Keywords Bayesian approach, GIS, epidemiology, geographical distribution, incidence, Type I diabetes.
The incidence of Type I (insulin-dependent) diabetes mellitus among children in Finland is the highest in the world [1], reaching 45 per 100000 person-years in 1996 [2]. During the last 30 years, the incidence has continuously increased by about $3 \%$ per year and during the early $1990 \mathrm{~s}$ the increase has been particularly steep $[2,3]$. This trend of increase in the inci-

Corresponding author: M. Rytkönen, University of Oulu, Department of Geography, P. O. BOX 3000, FIN-90014 University of Oulu, Finland

*see Acknowledgements

Abbreviations: GIS, Geographical Information System. dence of childhood diabetes is found not only in Finland and other populations with a high incidence but is a global phenomenon [4].

The geographical variation of the incidence of childhood diabetes is large $[1,5-8]$ and appears to reflect the distribution of ethnic populations across the globe demonstrating differences in the genetic susceptibility to Type I diabetes between populations [1, 6-13]. However, large differences in incidence have also been reported in populations living in relatively close proximity to one another who are genetically similar, for example the incidence rate in the Nordic Countries, in Finland, Sweden and Norway is two to four times higher than that in Estonia [1, 7, $14,15]$. Furthermore, within-country variation in the 
incidence of childhood diabetes has been reported in several European countries [16-25]. In Finland, a marked regional variation of childhood diabetes was reported during the late $1980 \mathrm{~s}$ [26].

Although genetic susceptibility is a precondition for the development of Type I diabetes, the wide global variation in incidence between and within ethnic groups suggests that environmental factors are an important cause of childhood diabetes [27]. A good understanding of geographical variation and of its link with the increase in the incidence of diabetes is essential to establish hypotheses on potential environmental risk factors for childhood diabetes. The aim of this study was to describe and compare the geographical distribution of incidence of Type I diabetes among Finnish children in two 5-year periods during 1987 to 1996 applying a full hierarchical Bayesian approach and the geo-referenced data on the population at risk and Type I diabetes.

\section{Subjects and methods}

Study area and population. The population of Finland is unevenly distributed. Only $25 \%$ of the population lives in the sparsely populated area that covers $95 \%$ of the total area of Finland while half of the population lives in major cities [28, 29]. The Finnish population aged 14 years or under varied from 952000 in 1987 to 972000 in 1997. The mid-year population of children aged 14 years or under for the years 1987, 1989, 1991, 1993, 1995 and 1997 was used as the denominator. The population data were obtained from the National Population Registry, which is updated continuously by Statistics Finland.

Study subjects. Data on the incidence of childhood Type I diabetes nationwide were obtained from the Prospective Childhood Diabetes Registry for the period 1987-1996 (3613 cases). Since 1987, all hospitals in Finland treating diabetic children have participated in the prospective registration of childhood Type I diabetes. Thus, all newly diagnosed subjects have been registered since 1987 [30]. The case ascertainment is virtually $100 \%$ complete $[2,3,30]$.

Geographical Information Systems (GIS) and geo-referenced data. Geographical Information Systems (GIS) deal with geographical information and consist of hardware, software, data, data management and outputs such as maps [31]. In GIS, the geographical data element is used to provide a reference for the statistical or non-locational data element [32].

Every resident in Finland has a unique personal identity number. The population data and children with diabetes were located at the time of diagnosis according to the map co-ordinates using identification (ID) numbers and GIS. Data were aggregated into grid cells with a resolution of $10 \cdot 10 \mathrm{~km}$ to protect the confidentiality of subjects.

Small area risk assessment: Bayesian disease mapping. The geographical distribution of the incidence of childhood diabetes was modelled separately for two 5-year periods 1987-1991 and 1992-1996 using a full hierarchical Bayesian approach [33]. Posterior mean incidence rates and posterior probabilities that the incidence will exceed the overall mean were calcu- lated for $10 \cdot 10 \mathrm{~km}$ grid cells. Thus, assessments of risk levels were based on the posterior distribution instead of crude maximum likelihood estimates [34].

The prior distribution of the incidence of childhood diabetes in a grid cell was defined as a Gaussian distribution of logarithm of estimated intensity of diabetes after conditioning on that of all the neighbouring cells. The prior mean incidence in a grid cell was defined as a mean of logarithm of estimated intensity of diabetes of the neighbours. The prior variance was inversely proportional to the number of neighbours. This prior definition is a conventional choice in spatial statistics and leads to Markov random field models requiring numerical computing techniques. In addition to a simple smoothing device, this prior variance also expresses the epidemiological assumption that the disease risks tend to be similar in neighbouring areas. This is due to spatially correlated, but unknown or unmeasured confounders, which contribute to contracting the disease. Neighbours were defined to be the nearest cells with a nonzero population at risk. The neighbours were identified with an algorithm in a growing spatial window until at least three populated cells were found. All the neighbourhood relations were defined to be symmetric.

We have made the subtle distinction between the observed incidence and the estimated intensity of diabetes. The former is the observed number of subjects per 100000 person-years. The latter is the underlying Poisson intensity upon which we made inferences from the data. Consequently, our inferences are based on quantifying the posterior geographical distribution of the rates, not on the observed incidence data alone.

The posterior estimated intensity of diabetes in a grid cell is only a point estimate and some high values simply correspond to the long tails of those marginal posterior distributions. The Bayesian posterior probability can be interpreted as a "Bayesian $p$-value". Therefore inferences from the results are partly based on the probabilities that the intensity in the area exceeds a certain threshold value. Here the threshold value was the observed mean incidence of childhood diabetes, 36.1 per 100000 person-years during the period 1987-1991 and 40 per 100000 person-years during the period 1992-1996.

The maps of estimated intensity of diabetes and the probability (estimated in $10 \cdot 10 \mathrm{~km}$ grid cells) for the periods 1987-1991 and 1992-1996 were done by categorising the estimated intensity and probability values using the same scale in both periods to get comparable maps. This scale was defined independently of distribution of the estimated values. The map of persistently high-intensity and low-intensity areas of childhood diabetes was done by categorising the estimated intensity into four classes each of them representing the quartiles of the intensity distribution. If the area belonged to the first quartile during both periods, it was defined as a persistently low-risk area. If the area belonged to the fourth quartile during both periods, it was defined as a persistently high-risk area.

\section{Results}

Observed incidence. During 1987 to 1996 the age-adjusted incidence of diabetes among Finnish children nationwide was 37.5 per 100000 per year. During the first 5-year period, from 1987 to 1991, the mean incidence was 36.1 per 100000 per year ranging from 34.0 to 39.2 per 100000 per year. During the second 5-year period, from 1992 to 1996, the mean incidence was 40.1 per 100000 per year ranging from 34.9 to 44.8 per 100000 per year (Table 1 ). There was a clear 
Table 1. Population and the age-adjusted incidence of Type I diabetes in children aged 14 years or under in Finland during 1987 to 1996 according to sex and year

\begin{tabular}{|c|c|c|c|c|}
\hline Year & Sex & Population & Subjects & $\begin{array}{l}\text { Incidence } \\
(100000 / \\
\text { year })\end{array}$ \\
\hline 1987 & $\begin{array}{l}\text { Male } \\
\text { Female } \\
\text { All }\end{array}$ & $\begin{array}{l}487218 \\
465725 \\
952943\end{array}$ & $\begin{array}{l}177 \\
158 \\
335\end{array}$ & $\begin{array}{l}36.4 \\
33.8 \\
35.1\end{array}$ \\
\hline 1988 & $\begin{array}{l}\text { Male } \\
\text { Female } \\
\text { All }\end{array}$ & $\begin{array}{l}490612 \\
469369 \\
959981\end{array}$ & $\begin{array}{l}180 \\
148 \\
328\end{array}$ & $\begin{array}{l}36.6 \\
31.1 \\
33.9\end{array}$ \\
\hline 1989 & $\begin{array}{l}\text { Male } \\
\text { Female } \\
\text { All }\end{array}$ & $\begin{array}{l}491934 \\
470335 \\
962269\end{array}$ & $\begin{array}{l}208 \\
144 \\
352\end{array}$ & $\begin{array}{l}42.5 \\
30.9 \\
36.8\end{array}$ \\
\hline 1990 & $\begin{array}{l}\text { Male } \\
\text { Female } \\
\text { All }\end{array}$ & $\begin{array}{l}492828 \\
471375 \\
964203\end{array}$ & $\begin{array}{l}165 \\
172 \\
337\end{array}$ & $\begin{array}{l}33.6 \\
36.6 \\
35.1\end{array}$ \\
\hline 1991 & $\begin{array}{l}\text { Male } \\
\text { Female } \\
\text { All }\end{array}$ & $\begin{array}{l}493375 \\
472223 \\
965598\end{array}$ & $\begin{array}{l}204 \\
174 \\
378\end{array}$ & $\begin{array}{l}41.5 \\
36.8 \\
39.2\end{array}$ \\
\hline 1992 & $\begin{array}{l}\text { Male } \\
\text { Female } \\
\text { All }\end{array}$ & $\begin{array}{l}494804 \\
473476 \\
968280\end{array}$ & $\begin{array}{l}179 \\
153 \\
332\end{array}$ & $\begin{array}{l}36.5 \\
32.5 \\
34.5\end{array}$ \\
\hline 1993 & $\begin{array}{l}\text { Male } \\
\text { Female } \\
\text { All }\end{array}$ & $\begin{array}{l}495839 \\
474890 \\
970729\end{array}$ & $\begin{array}{l}176 \\
155 \\
331\end{array}$ & $\begin{array}{l}35.1 \\
32.6 \\
33.9\end{array}$ \\
\hline 1994 & $\begin{array}{l}\text { Male } \\
\text { Female } \\
\text { All }\end{array}$ & $\begin{array}{l}496671 \\
475573 \\
972244\end{array}$ & $\begin{array}{l}197 \\
201 \\
398\end{array}$ & $\begin{array}{l}39.4 \\
42.3 \\
40.8\end{array}$ \\
\hline 1995 & $\begin{array}{l}\text { Male } \\
\text { Female } \\
\text { All }\end{array}$ & $\begin{array}{l}496307 \\
475463 \\
971770\end{array}$ & $\begin{array}{l}184 \\
212 \\
396\end{array}$ & $\begin{array}{l}37.2 \\
43.4 \\
40.2\end{array}$ \\
\hline 1996 & $\begin{array}{l}\text { Male } \\
\text { Female } \\
\text { All }\end{array}$ & $\begin{array}{l}494759 \\
473808 \\
968567\end{array}$ & $\begin{array}{l}237 \\
196 \\
433\end{array}$ & $\begin{array}{l}48.1 \\
41.3 \\
44.8\end{array}$ \\
\hline
\end{tabular}

geographic variation in observed incidence rates of Type I diabetes among children in Finland during the periods 1987-1991 and 1992-1996. However, the observed incidence rates calculated in the small-areas $(10 \mathrm{~km} \cdot 10 \mathrm{~km})$ were not stable and varied largely. Therefore the maps of observed incidences were violated by uncontrolled random variation in the rates and were thus misleading (Fig.1A-B).

Geographical pattern of the occurrence of diabetes. There was a fairly continuous high-risk area (posterior estimated intensity greater than 36.1 per 100000 per year) covering most of the middle part of the country, reaching from the western coast to the eastern border of Finland during 1987-1991 (Fig.2A). However, a narrow low-risk gap (posterior estimated intensity $<36.1$ per 100000 per year) following the south coastal area and extending up to northern Finland split the high-risk area into two separate areas. In addition, another distinct high-risk area was found in the proximity to the north-eastern border of Finland. The high-risk areas of Type I diabetes remained mainly the same and between 1987 and 1991 and 1992 and 1996 (Fig. 2B). The low-risk area, i.e. the gap between the two high-risk areas in central Finland, had disappeared and there were three areas of high intensity for Type I diabetes (posterior estimated intensity greater than 50 per 100000 per year) in the middle part of the country.

During 1992 to 1996, the overall mean incidence of Type I diabetes was clearly higher than during 1987 to 1991. The spatial pattern of the intensity of diabetes showed that the risk increased in the central part of the country. The western high-risk area expanded southward and eastward creating a continuous belt crossing central Finland. In the north-eastern part of the country the high-risk area vanished and a new high-risk area was found in the north-western part of Finland (Fig. 2A-B).

To confirm the credibility of the geographical pattern of the occurrence of diabetes displayed in the maps of intensities of diabetes (Fig. 2A-B) the maps of the "Bayesian $p$-value" for the estimated intensities of Type I diabetes (Fig. 3A-B) were produced. The maps show the probability of the disease risk exceeding the observed mean incidence during each 5year period (36.1 per 100000 per year during 1987 to 1991 and 40.0 per 100000 per year during 1992 to 1996).

Persistently high and low risk areas. In the period 1987-1991 the definitions of the area with a low risk of diabetes corresponded to the grid cells where the estimated intensities were between $19.7-33.8$ per 100 000 per year and the high-risk area corresponded to the grid cells with intensities 42.0 per 100000 per year or more. In the period 1992-1996 the definition of a low-risk area was 1.4-35.7 per 100000 per year and that of a high-risk area was 48.8 per 100000 per year or more. The risk of childhood diabetes remained high over this entire 10 -year period in the easternmost part of Finland, in mid-western Finland and in smaller pockets in southern Finland. During the latter period from 1992 to 1996, the estimated intensity of childhood diabetes in these areas exceeded 50 per 100000 per year. Several areas where the risk was persistently low during both periods were scattered in various parts of the country (Fig.4).

\section{Discussion}

There was a clear geographic variation in the risk for Type I diabetes among children aged 14 years or under in Finland in 1987-1996. Most of the high-risk areas were in the wide belt crossing the central part of Finland. This finding confirms our previous study [26] and can be seen in both 5-year observation periods. In these high-risk areas specific genetic, and possibly also common environmental risk factors, caus- 


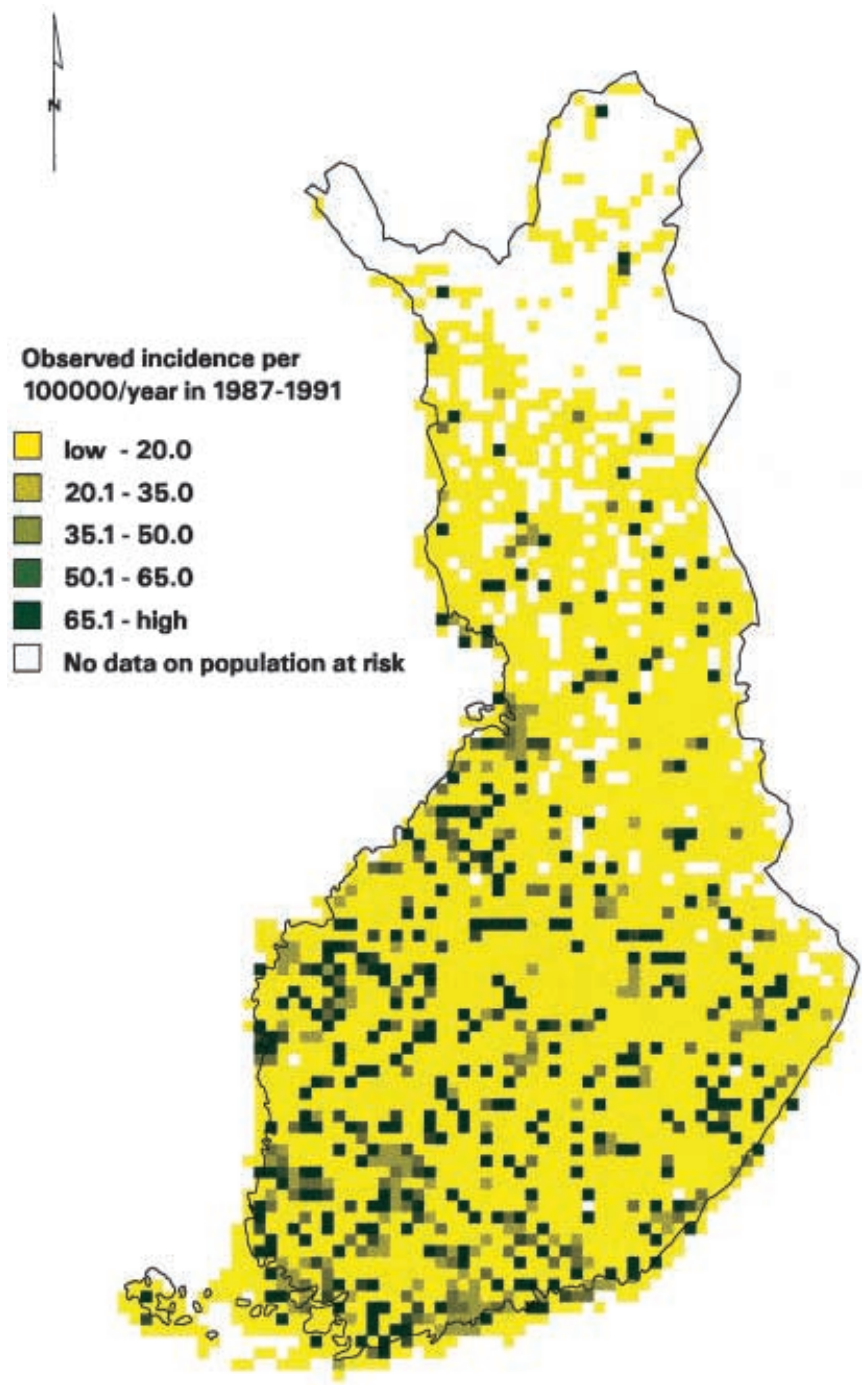

A

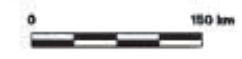

Fig. 1. The observed incidence of Type I diabetes among children aged 14 years or under in Finland during A) 1987 to 1991 and B) 1992 to 1996 . The analysis was carried out using geo-referenced data at a resolution of $10 \cdot 10$ kilometres. (Map: University of Oulu, Department of Geography)

ing the disease are likely to exist. Although there were similarities in the spatial risk pattern of Type I diabetes during the two 5-year periods, the pattern did not remain stable. This finding indicates that the onset of childhood diabetes is associated with non-genetic environmental risk factors. However, the changes of the geographical pattern of risk in northern Finland could be due more to the inability of the model to reduce the variation of the estimates because the population at risk was small in the northern part of the country.

Although Type I diabetes is common in Finland, it has not often been examined from the view of geographic health research. According to the prelimi-

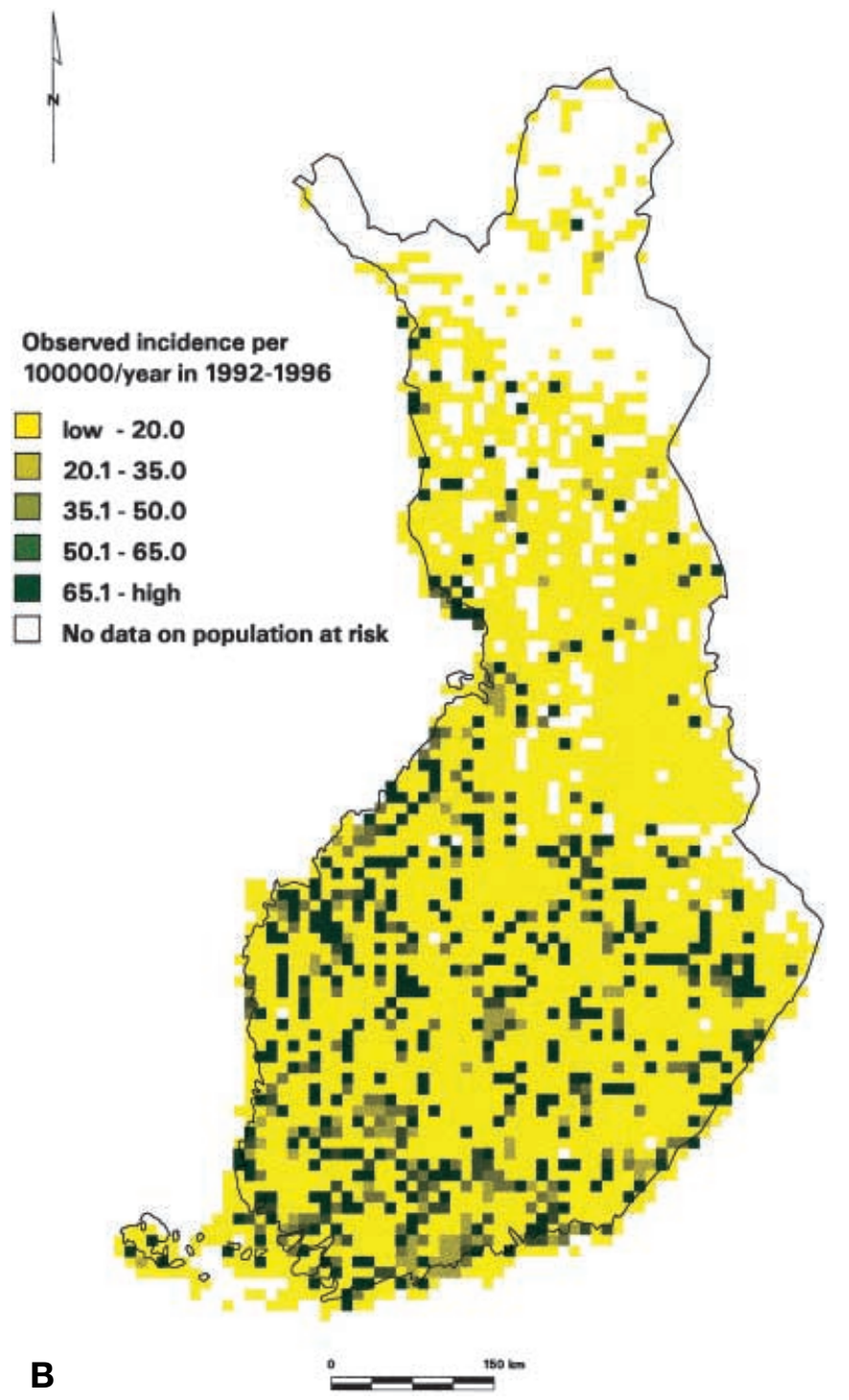

nary studies [33] the resolution of $100 \mathrm{~km}^{2}$ was an appropriate choice for the study unit in order to describe the variation of risk of diabetes. However, working on such a geographic scale exacerbated the problem of extra Poisson variability. More stable rates could be obtained at regional or county level but this scale would have faded out important information of small area variation [35]. Therefore the Bayesian approach was used to reduce the random variation of the observed incidence [31, 36, 37]. The Bayesian approach relies on the conventionally used Markov random field model, which defines the prior probability structure of the underlying (theoretical) spatial disease intensities. As a result, the posterior mean intensities represent the plausible expected values of disease intensities, i.e. they are a compromise between the observed incidence value in a grid cell and the observed values in the neighbourhood of that grid cell (local). The amount of smoothing is controlled by a model parameter, which is also jointly estimated from the data. There is no 'correct' disease 


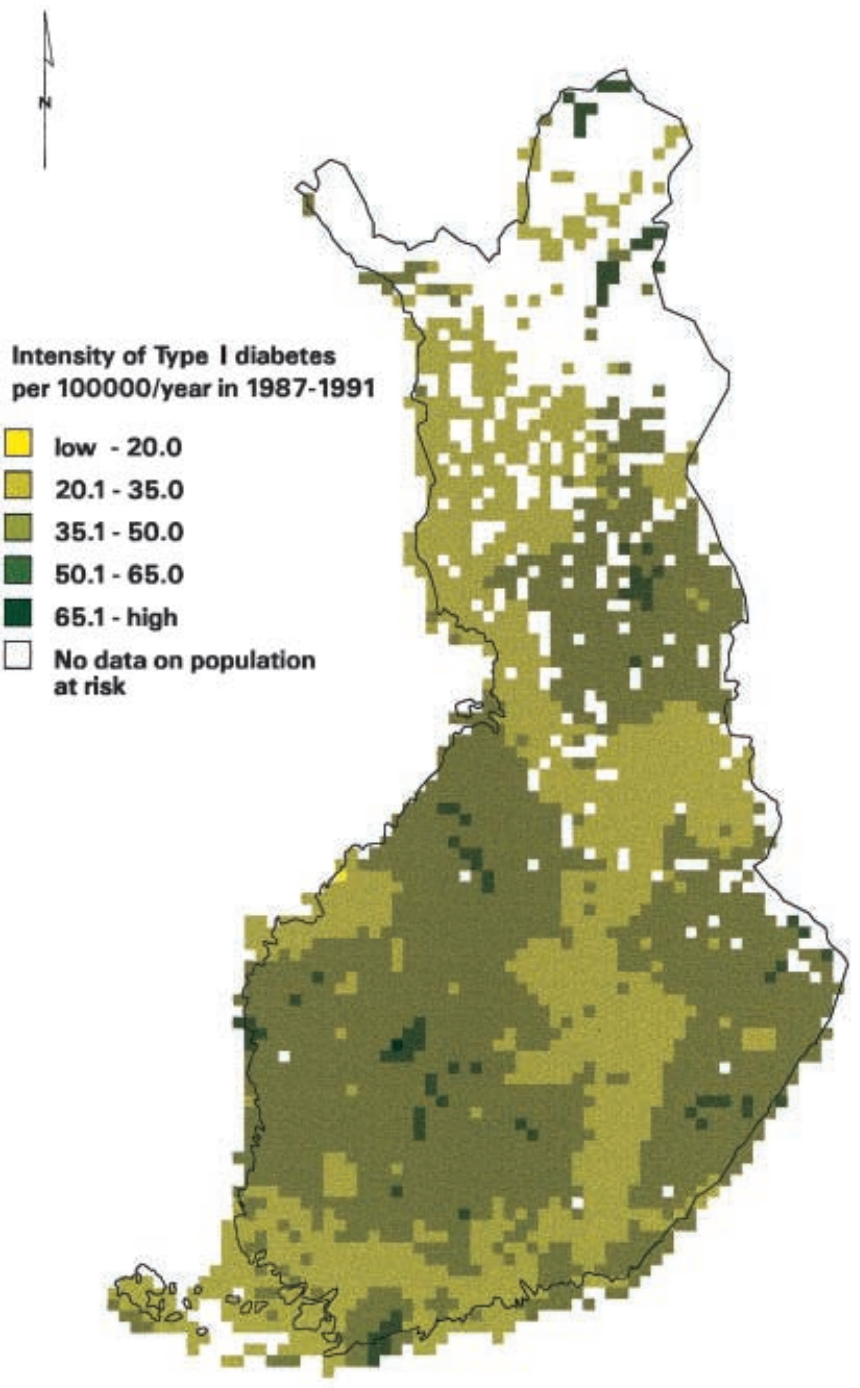

A

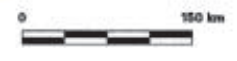

Fig. 2. The posterior means of Type I diabetes intensity among children aged 14 years or under in Finland during A) 1987 to 1991 and B) 1992 to 1996. The means were computed from a Bayesian (CAR) model with grid cells of $10 \cdot 10 \mathrm{~km}$. (Map: University of Oulu, Department of Geography)

map in any absolute sense [38] but there are possibilities for assessing the performance of a model. For example, the model fit could be studied by calculating the sum of pixel-wise squared errors. The smallest possible error would be achieved by not smoothing at all, which is not a preferable option. However, another possibility for assessing the model's performance would be to use cross-validation techniques: a part of the data is first erased and the remaining data is used to produce predictive distributions for the erased part. In this way, it is possible to compare model based predictions with actual observations in any defined small area on the disease map [33]. Unfortunately, the number of all possible sets of pixels

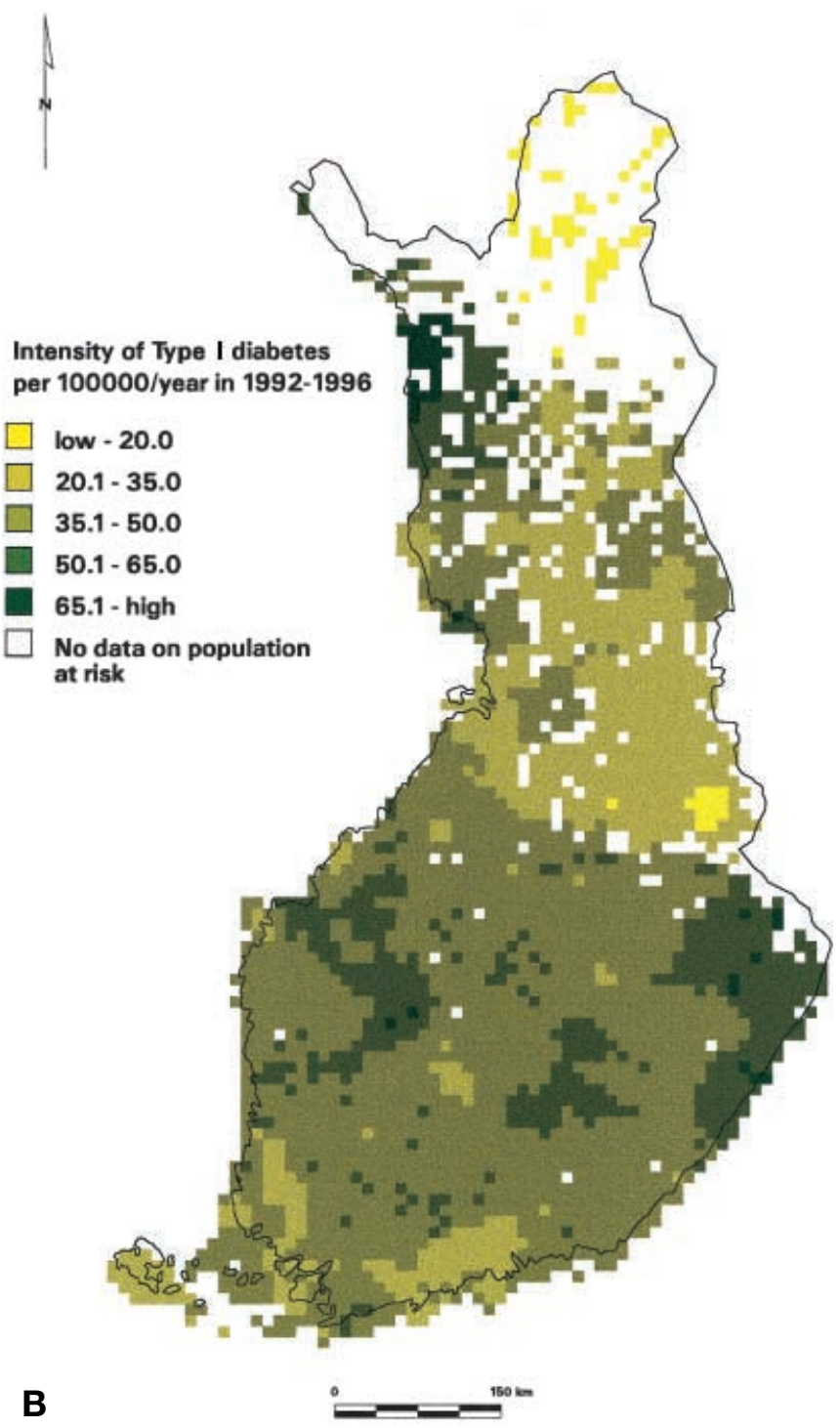

that could be used for the predictions is huge. Therefore deciding in advance a set of small areas included in a cross validation process seems to be the best option.

The measurement of real magnitude of exposure is difficult without a longitudinal study design. A geographic analysis can only indicate that there might be a connection between an environmental agent and disease occurrence. One of the most difficult problems in using geographical analysis for health research is that subjects with a chronic disease could have been exposed to potential risk factors much earlier and in a different location than that in which the first signs of the disease were seen. Thus, exposures and risks experienced earlier in the life could become associated on maps with an inaccurate geographic location. Therefore, it would have been interesting to see whether age-specific spatial patterns of Type I diabetes for different age-at-onset groupings differ from each other. Especially, the geographical analysis restricted to children $0-4$ years of age might have 


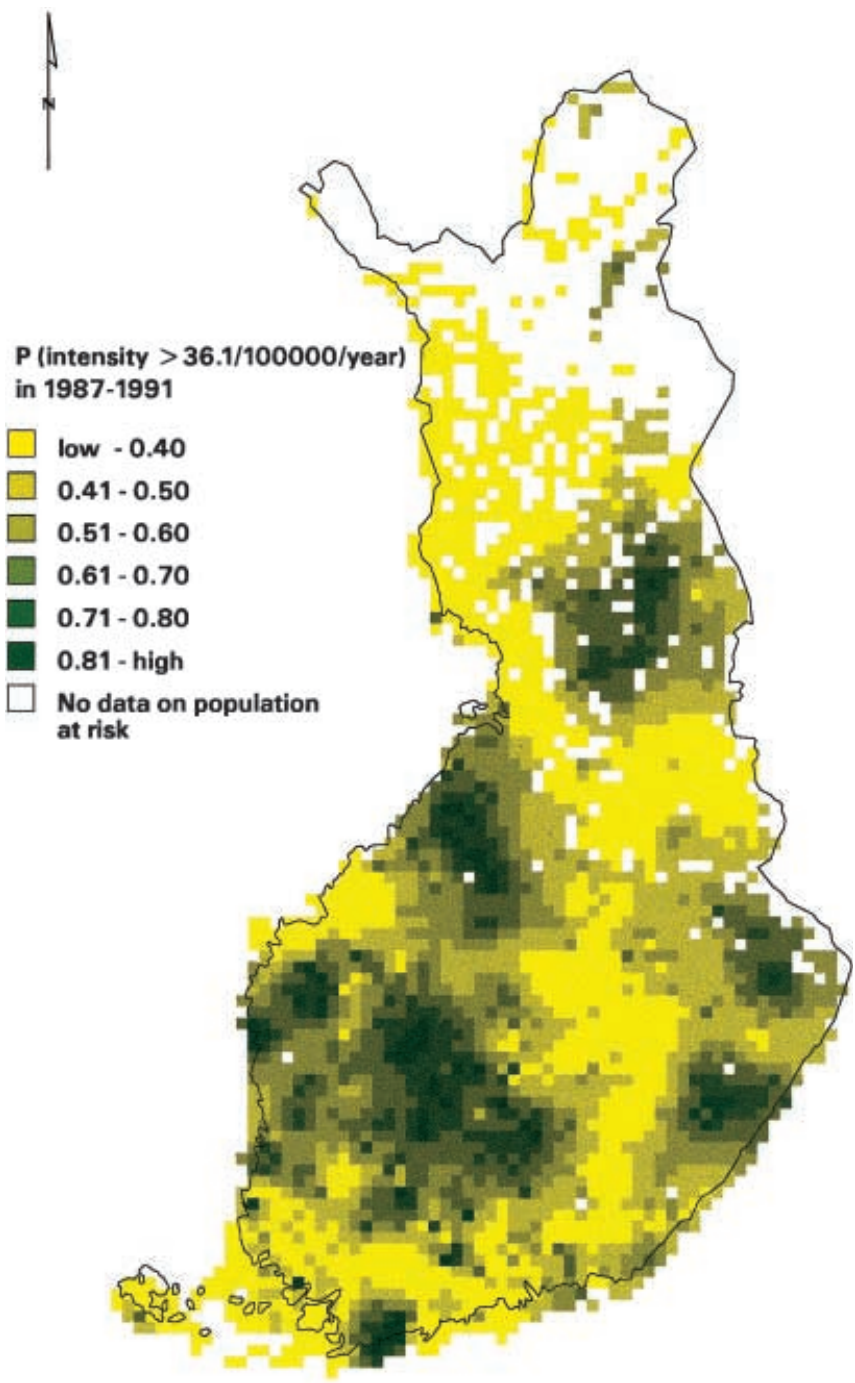

A

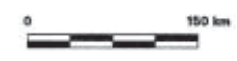

Fig.3. Geographical pattern of the posterior probability $(\mathrm{P})$ that the intensity of Type I diabetes in the grid cell was higher than the mean intensity of diabetes A) during 1987 to 1991 and B) during 1992 to 1996 among children aged 14 years or under in Finland. The mean was 36.1 per 100000 per year during 1987 to 1991 and 40.0 per 100000 per year during 1992 to 1996. (Map: University of Oulu, Department of Geography)

brought important information about the cause of Type I diabetes but there were not enough subjects in age group of 0-4 years for a proper spatial analysis. We therefore excluded an analysis from this study.

Several common environmental factors, such as dietary factors or viral infections [39-42], triggering Type I diabetes have been discussed. Thus far none of them have been proven to be an underlying cause of childhood diabetes. The high intake of nitrites and nitrates or some other elements in the diet might have an influence on regional differences of the occurrence of childhood diabetes in Finland. For this reason the content of certain trace elements in drink-

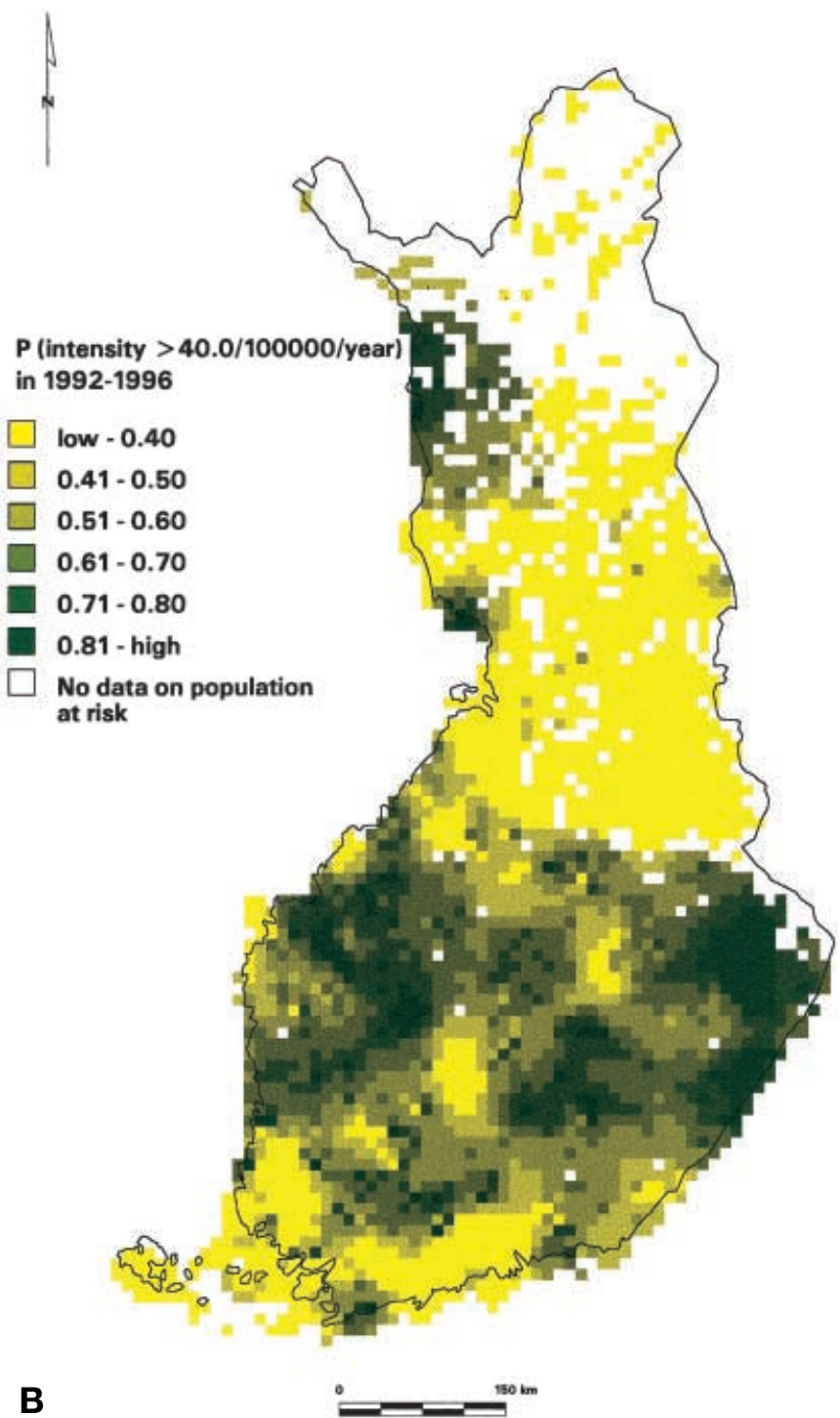

ing water in the areas where the incidence stayed persistently high during the 10 -year period will be examined in the near future.

The population density is highest in the southernmost part of the country. However, the risk of childhood diabetes in this area is low when compared with the risk in the more sparsely populated area of central Finland. Furthermore, a previous study on the spatial pattern of Type I diabetes incidence in Finland 1997 [26] showed a strong negative correlation between the population density and the risk of childhood diabetes. A lower incidence of childhood diabetes among children living in urban areas has been reported in England [22]. On the other hand, findings reported in Italy suggested that people living in the rural communities had a lower risk of Type I diabetes [24]. Thus it seems that the degree of urbanization might not have an effect on the risk for Type I diabetes.

There was a clear and stable regional difference in the risk for Type I diabetes among children aged 


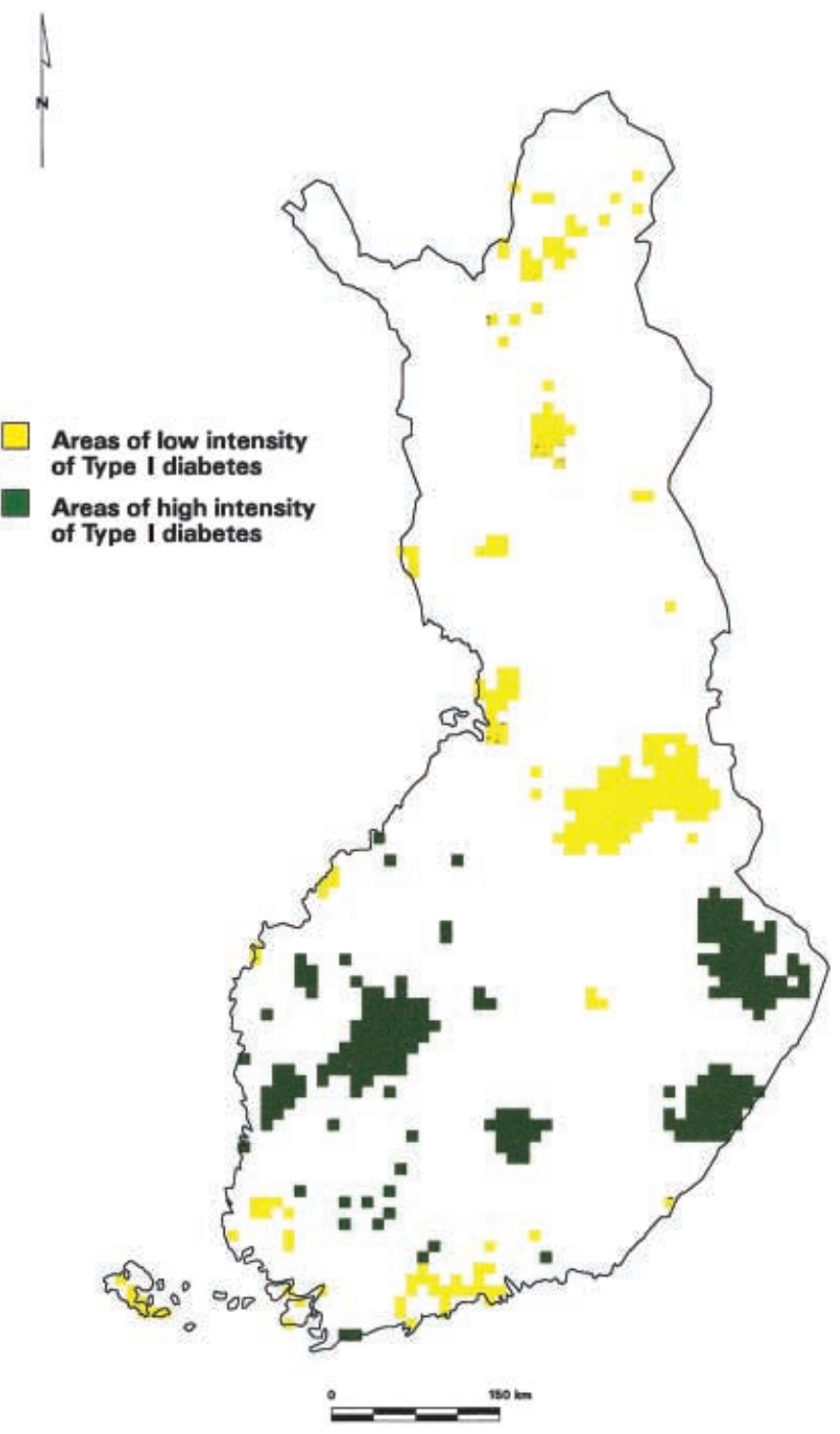

Fig.4. Areas with persistently high risk (estimated intensity 42.0 per 100000 per year or more) and persistently low risk (estimated intensity 35.7 per 100000 per year or under) of Type I diabetes in Finland during the two 5-year periods from 1987 to 1991 and from 1992. (Map: University of Oulu, Department of Geography)

14 years or under in Finland. The persistently highrisk areas were found in central Finland. The focus of subsequent epidemiological studies will be on those small areas with high rates in Finland. Several aspects of genetic and environmental factors will be examined more closely in our further geographical studies of Type I diabetes.

Acknowledgements. This work was partly funded by the Academy of Finland (project No. 41266 and the NIH-grant DK-37957). The data were provided by the diabetes research unit at the National Public Health Institute, Finland, computing facilities by the Rolf Nevanlinna Institute, University of Helsinki and GIS-facilities by the Department of Geography, University of Oulu, Finland.
The SPAT-Project Research Group:

Principal investigator: M. Karvonen

Investigators: A. Kousa, J. Ranta, M. Rytkönen, M. Viik-Kajander

Steering group: E. Arjas, U. Häkkinen, M. Nenonen, O. Nylander, J. Pekkanen, A. Penttinen, J. Rusanen, R. Salminen, T. Tarvainen, J. Tuomilehto

The Finnish Childhood IDDM Registry group:

A. Fagerlund, M. Flittner, P. Floman, B. Gustafsson, H. Haavisto, T. Huupponen, P. Hiltunen, M. Hyttinen, R. Jokisalo, U. Kaski, J. Komulainen, P. Korpela, M-L. Käär, J. Lappalainen, P. Lautala, P. Lehtinen, E. Lehtokoski-Lehtiniemi, M. Lipsanen-Nyman, K. Niemi, A. Nuuja, P. Ojajärvi, J. Ollikainen, A. Putto-Laurila, S. Pöntynen, J. Sankala, T. Sillanpää, I. Sipilä, P. Tapanainen, A. Tomminen, T. Uotila, P. Varimo, P. Vuolukka, M. Väre.

\section{References}

1. Karvonen M, Tuomilehto J, Libman I, LaPorte R (1993) A review of the recent epidemiological data on the worldwide incidence of Type I (insulin-dependent) diabetes mellitus. World Health Organization DIAMOND Project Group. Diabetologia 36: 883-892

2. Tuomilehto J, Karvonen M, Pitkäniemi J et al. (1999) Record-high incidence of insulin-dependent diabetes mellitus (IDDM) in Finnish children. Diabetologia 42: 655-660

3. Tuomilehto J, Virtala E, Karvonen M et al. (1995) Increase in incidence of insulin-dependent diabetes mellitus among children in Finland. Int J Epidemiol 5: 984-992

4. Onkamo P, Väänänen S, Karvonen M, Tuomilehto J (1999) Worldwide increase in incidence of IDDM - meta-analysis of the recent published incidence data. Diabetologia 42: 1395-1403

5. Diabetes Epidemiology Research International Group (1988) Geographic patterns of childhood insulin-dependent diabetes mellitus. Diabetes 37: 1113-1119

6. Rewers M, LaPorte RE, King H, Tuomilehto J, DERIgroup (1990) Trends in the prevalence and incidence of diabetes: insulin-dependent diabetes mellitus in childhood. World Health Stat Q 41: 179-189

7. Green A, Gale EA, Patterson CC (1992) Incidence of childhood-onset insulin-dependent diabetes mellitus: the EURODIAB ACE Study. Lancet 339: 905-909

8. Karvonen M, Pitkäniemi M, Pitkäniemi J, Kohtamäki K, Tajima N, Tuomilehto J (1997) Sex difference in the incidence of insulin-dependent diabetes mellitus: an analysis of the recent epidemiological data. World Health Organization DIAMOND Project Group. Diabetes Metab Rev 13: 275-291

9. McLarty DG, Swai ABM, Kitange HM et al. (1989) Prevalence of diabetes and impaired glucose tolerance in rural Tanzania. Lancet i: 871-875

10. MacDonald MJ (1975) Lower frequency of diabetes among hospitalized Negro than white children: theoretical implications. Acta Genet Med Gemellol (Roma) 24: 119-125

11. MacDonald MJ (1980) Hypothesis: the frequencies of juvenile diabetes in American blacks and Caucasians are consistent with dominant inheritance. Diabetes 29: 110-114

12. Reitnauer PJ, Go RCP, Acton RT et al. (1982) Evidence for genetic admixture as a determinant in the occurrence of insulin-dependent diabetes mellitus in U.S. blacks. Diabetes 31: 532-537 
13. Chakraborty R, Kamboh MI, Nwankwo M, Ferrell R (1992) Caucasians genes in American Blacks: new data. Am J Hum Genet 50: 145-155

14. Dahlquist G, Mustonen L (1994) Childhood onset diabetes-time trends and climatological factors. Int $\mathrm{J}$ Epidemiol 23: $1234-1241$

15. Padaiga Z, Tuomilehto J, Karvonen M et al. (1997) Incidence trends in childhood onset IDDM in four countries around the Baltic Sea during 1983-1992. Diabetologia 40: 187-192

16. Joner G, Sovik O (1989) Increasing incidence of diabetes mellitus in Norwegian children 0-14 years of age 1973-1982. Diabetologia 32: 79-83

17. Metcalfe M, Baum J (1991) Incidence of insulin dependent diabetes in children aged under 15 years in the British Isles during 1988. BMJ 302: 443-447

18. Patterson C, Waugh N (1993) Urban/rural and deprivational differences in incidence and clustering of childhood diabetes in Scotland. Int J Epidemiol 21: 352-358

19. Patterson C, Carson D, Hadden D (1996) Epidemiology of childhood IDDM in Northern Ireland 1989-1994: low incidence in areas with highest population density and most household crowding. Diabetologia 39: 1063-1069

20. McKinney PA, Law GR, Bodansky HJ, Staines A, Williams DRR (1996) Geographical Mapping of Childhood Diabetes in the Northern English County of Yorkshire. Diabet Med 13: 734-740

21. Cherubini V, Chiarelli F, Altobelli E, Verrotti A, Carle F (1997) Regional variability in the epidemiology of childhood diabetes in Italy. J Pediatr Endocrinol Metab 10: 471-478

22. Staines A, Bodansky HJ, McKinney PA et al. (1997) Small area variation in incidence of childhood insulin-dependent diabetes mellitus in Yorkshire, UK: Links with overcrowding and population density. Int J Epidemiol 28: 1307-1313

23. Songini M, Bernardinelli L, Clayton D et al. (1998) The Sardinian IDDM study: Epidemiology and geographical distribution of IDDM in Sardinia during 1989 to 1994. Diabetologia 41: 221-227

24. Cherubini V, Carle F, Gesuita R et al. (1999) Large incidence variation of Type I diabetes in central-southern Italy 1990-1995: lower risk in rural areas. Diabetologia 42: 789-792

25. Rosenbauer J, Herzig P, Kries von R, Neu A, Giani G (1999) Temporal, seasonal, and geographical incidence patterns of Type I diabetes mellitus in children under 5 years of age in Germany. Diabetologia 42: 1055-1059

26. Karvonen M, Rusanen J, Sundberg M et al. (1997) Regional Differences in the Incidence of Insulin-dependent Diabetes Mellitus among Children in Finland from 1987 to 1991. Ann Med 29: 297-304
27. Leslie DG, Elliot RB (1994) Early environmental events as a cause of IDDM. Diabetes 43: 843-850

28. Rusanen J, Räisänen S, Naukkarinen A, Colpaert A (1995) Definition of rural areas based on primary production by means of GIS. Terra 107: 101-111

29. Rusanen J, Naukkarinen A, Colpaert A (1993) Square kilometer grid system: an efficient database in rural studies. Geogr Res Forum 13: 129-138

30. Tuomilehto J, Lounamaa R, Tuomilehto-Wolf E et al. (1992) Epidemiology of childhood diabetes mellitus in Finland - background of a nationwide study of Type I (insulin -dependent) diabetes mellitus. Diabetologia 35: 70-76

31. Croner C, Sperling J, Broome F (1996) Geographic information systems (GIS): new perspectives in understanding human health and environmental relationship. Stat Med 15: 1961-1977

32. Maguire DJ (1991) An overview and definition of GIS. In: Maguire D, Goodchild M, Rhind D (eds) Geographical information systems: Principles and applications. Vol 1, Principles. Longman, Essex, pp 9-20

33. Ranta J, Penttinen A (2000) Probabilistic small area risk assessment using GIS-based data: a case study on Finnish childhood diabetes. Stat Med 19: 2345-2359

34. Bernardinelli L, Montomoli C (1992) Empirical Bayes versus fully bayesian analysis of geographical variation in disease risk. Stat Med 11: 983-1007

35. Wittie P, Drane W, Aldrich T (1996) Classification methods for denominators in small areas. Stat Med 15: 1921-1926

36. Clayton D, Bernardinelli L (1992) Bayesian methods for mapping disease risk. In: Elliot P, Cuzick J, English D, Stern R (eds) Geographical and Environmental Epidemiology: Methods for Small-Area Studies. Oxford University Press, Oxford, pp 205-220

37. Clayton D, Kaldor J (1987) Empirical Bayes estimates of age-standardized relative risks for use in disease mapping. Biometrics 43: 671-682

38. Gelman A, Price P (1999) All maps of parameter estimates are misleading. Stat Med 18: 3221-3234

39. Dahlquist G, Blom L, Persson L, Sandstrom A, Wall S (1990) Dietary factors and the risk of developing insulin dependent diabetes in childhood. BMJ 300: 1302-1306

40. Virtanen S, Jakkola L, Räsänen L, and the Childhood diabetes Study Group in Finland (1993) Nitrate and nitrite intake and the risk for type 1 diabetes in Finnish children. Diabet Med 11: 656-662

41. Dahlquist G (1998) The aetiology of Type 1 diabetes: an epidemiological perspective. Acta Paediatr Suppl 425: 5-10

42. Szopa TM, Titchener P, Portwood N et al. (1993) Diabetes mellitus due to viruses -some recent developments. Diabetologia 34: 282-287 